\title{
EDITORIAL
}

Zilda Gaspar Oliveira de Aquino e Maria Inês Batista Campos

Universidade de São Paulo, São Paulo, SP, Brasil

\section{O poder do discurso em diferentes saberes}

Refletir sobre o real funcionamento dos discursos, tendo em vista as relações de poder que se instauram entre os participantes de determinadas esferas ou domínios discursivos que se entrecruzam, constitui a proposta central deste número da revista Linha D'Água. Além disso, destaca-se que os artigos publicados resultam de pesquisas apresentadas durante evento organizado conjuntamente por pesquisadores do Programa em Filologia e Língua Portuguesa da Universidade de São Paulo e do Centro de Linguística da Universidade de Porto, realizado na cidade do Porto, de 26 a 28 de outubro de 2016.

O evento acadêmico correspondeu às VI Jornadas Internacionais de Análise do Discurso (VI JADIS) e ao II Congresso Internacional de Estudos do Discurso (II CIED) e teve por objetivo reunir pesquisadores de várias universidades da Europa e do Brasil que abordassem o discurso em várias esferas - jurídica, política, midiática, acadêmica, pedagógica - como objeto de investigação. Buscou abrir um espaço de reflexão sobre os discursos do poder nas suas formas possíveis em sociedade, focalizando o discurso como potenciador de mudança e de construção de modelos alternativos de prática social.

Partiu do pressuposto de que a noção de discurso enquanto exercício de poder está desde sempre presente nas várias correntes dos Estudos do Discurso, sejam a chamada Escola Francesa de Análise do Discurso, a Análise Crítica do Discurso, 
Linha D’Água (Online), São Paulo, v. 30, n. 1, p. 1-7, jun. 2017

entre outras. Corresponde a uma área de estudos extremamente interdisciplinar, tendo em vista ser de interesse também das Ciências Sociais, da Sociologia, da Filosofia, entre outras. Focalizou tanto o poder como dominação, quanto a questão de atribuição de poder, de empoderamento nas relações sociais.

O evento transcorreu num momento marcado por intensos problemas sociais, econômicos e políticos no mundo e, assim, os debates a respeito de discurso e poder possibilitaram reflexão premente no que diz respeito à compreensão das práticas discursivas que se apresentam.

Destaca-se, ainda, que se criou um espaço de discussão que perpassou o discurso do poder de caráter institucional-político, jurídico, como também o contexto de sala de aula, o familiar e o religioso, em que foram observados os vários níveis da construção textual, do cotextual ao não-verbal.

O tema "O poder do discurso e o discurso do poder" foi projetado para assumir um caráter transdisciplinar, de modo a possibilitar um diálogo entre diferentes correntes dos estudos do discurso. Assim, entende-se que as discussões em torno de questões epistemológicas e metodológicas das pesquisas de língua portuguesa que serviram de base para a compreensão da organização do discurso, da interação, da argumentação, do contexto, entre outros, certamente contribuirão para o desenvolvimento de investigações que se esperam surgir das discussões deste volume.

Compreende-se, também, que nas mais diversas esferas de circulação do discurso convivem representações de força, aqui instanciadas como relações de poder. Consiste de revestir o discurso de um matiz tal em que o caráter substancial de poder repouse nas concepções que se elejam como verdadeiras. Não se deve entender o discurso do poder reduzido apenas à instância do poder político, mas também ao poder do discurso de outras instituições, públicas ou privadas, de tal modo que possa perpassar as esferas já indicadas.

Observa-se, assim, que a instância cidadã pode-se ver envolvida, nos diversos contextos do dia a dia, pelo discurso de um sistema organizacional frente ao discurso de outro sistema organizacional que se integram num sistema funcional pela busca do poder (AQUINO, 2015). Nessa direção, está-se face ao (s) percurso (s) que se delineia $(\mathrm{m})$ nessas práticas discursivas, revestidas de marcas linguísticas 
Linha D’Água (Online), São Paulo, v. 30, n. 1, p. 1-7, jun. 2017

norteadoras, que se constituem em pistas para que cheguemos ao jogo estratégico que dimensiona o discurso e suas relações de poder.

A complexidade inerente às práticas discursivas, constituídas nas diferentes esferas de circulação dos discursos, e o modo como se imbricam merecem ser registradas, compreendidas pelo mundo da pesquisa que se faz a partir das sociedades que o envolvem. Nessa acepção, entende-se que o discurso de algumas esferas convive como representações de força, passíveis de serem observadas a partir das diversas ações praticadas que não só as linguageiras.

Além do exposto, é necessário lembrar que, nessas práticas do discurso, em condições específicas da vida pública, cada qual age e reage discursivamente para fins definidos e determinados a partir daquilo que imagina do outro. Essa postura correlaciona-se a configurações de épocas distintas e é efetivada por sujeitos sociais, os quais defendem e falam em nome de valores e, assim, assumem identidades não de modo estável e limitado, mas sim adaptável e múltiplo, sobretudo, por conta tanto dos vários papéis assumidos por eles na sociedade, quanto dos lugares de que seus discursos são produzidos.

Por outro lado, as estruturas dos sistemas sociais estão disponíveis para todos; o modo de participação entre os indivíduos é que possibilita ao analista do discurso o reconhecimento dos caminhos tomados para a constituição das relações de poder que se apresentam.

Buscar compreender a concepção de relação de poder no discurso significa observá-lo de maneira que se apreenda muito mais do que aquilo que ele explicita - Voloshinov (1981) já apresentava a concepção de que um enunciado se constitui de palavras e da parte presumida; significa buscar o jogo que se interpõe entre os interlocutores a partir do se formula - o que parece fundamental em qualquer atividade discursiva. A atribuição de sentido ao discurso corresponde, assim, a observá-lo como atividade que transcorre no seio da sociedade e que se estabelece intersubjetivamente no jogo das ações linguageiras, em que estão previstas aceitação/ recusa, contenção/inovação, algo a ser negociado e transformado, dependendo do contexto social (FAIRCLOUGH; WODAK, 1997) e das relações que se estabelecem entre os participantes. 
$\mathrm{Na}$ verdade, são muitos os caminhos teóricos que poderiam ser buscados para, metodologicamente, compreendermos o discurso: desde Foucault (1987, p. 104) para quem "O referencial do enunciado forma o lugar, a condição, o campo de emergência, a instância de diferenciação dos indivíduos ou dos objetos, do estado das coisas e das relações que são postas em jogo pelo próprio enunciado [...]", perpassando a perspectiva interacionista - base para observação de variáveis específicas, quais sejam o papel discursivo (que autoriza ou não o dizer), o objetivo do encontro e quem são os interlocutores (alcance do discurso), conforme Kerbrat -Orecchionni (1986), até alcançar, entre outros, Bauman (2005) que nos lembra o fato de que o Estado, após a globalização, perdeu o poder de manutenção da união sólida e inabalável com sua nação.

A partir dessa perspectiva, o trabalho é maior e o controle tornou-se mais difícil para os que buscam deter o poder pelo discurso. Antecederam as discussões desse estudioso, os trabalhos de Hall (1999) que afirmara o quanto o mundo ficara menor com a globalização. Se ficou menor em termos de circulação de ideias e valores, complexizou-se quanto às relações que se estabelecem no/pelo discurso.

Os trabalhos que se apresentam neste volume 30 (1) buscam, assim, refletir sobre o funcionamento do discurso, tendo em vista contextos específicos em que participantes estão no exercício do poder e ocupam cargos máximos na política (presidente, primeiro-ministro, patronato), além de participantes que estão à frente de salas de aula e, ainda, participantes que estão à frente da mídia jornalística, ou ainda à frente dos discursos artísticos conforme se apresenta a seguir.

O artigo de Maria Aldina Marques (Universidade do Minho/Braga) Debate eleitoral português: presidencialização e estratégias de atenuação linguística em situação de confronto político coloca em pauta um tema caro à contemporaneidade: o debate político eleitoral televisivo em Portugal para as eleições legislativas, ocorrido em maio de 2011. A autora propõe uma discussão em torno do debate eleitoral como gênero do discurso político marcado pelas relações com o discurso mediático televisivo. Destaca nele a atenuação linguística como estratégia usada ao longo do debate para atenuar o efeito de agressividade entre os candidatos, construindo uma imagem de credibilidade para garantir êxito nas eleições. 
Linha D'Água (Online), São Paulo, v. 30, n. 1, p. 1-7, jun. 2017

Maria Alexandra Pinto, Ana Catarina Pinho e Joana Teixeira, do Centro de Linguística da Universidade do Porto, em Polarização e construção da força discursiva em manifestos politicos: o caso das presidenciais portuguesas de 2016, trazem uma análise do manifesto político de um candidato às eleições presidenciais portuguesas de janeiro de 2016. As autoras propõem uma descrição minuciosa da organização argumentativa como força discursiva, enfatizando a descrição do manifesto político como gênero de texto, pertencente ao tipo de discurso político.

Carla Aurélia Almeida (Universidade Aberta/ Universidade do Porto), em O poder dos discursos do patronato portuense nas sessóes comemorativas de aniversários: rituais verbais, argumentação e configuração enunciativa, apresenta uma análise minuciosa de notícias sobre a comemoração de aniversários da Associação Industrial Portuense publicados na revista $A$ Indústria do Norte (1949-1970) a fim de recuperar a imagem do locutor. A partir da perspectiva semântico-pragmática, a autora foca nas estratégias de argumentação usadas pelos representantes dos patrões para mostrar como eles constroem o jogo argumentativo, demonstrando uma tomada de posição do patronato portuense.

O artigo de Dóris de Arruda Carneiro Cunha, da Universidade Federal de Pernambuco e da Universidade Católica de Pernambuco, intitulado Um olhar sobre vozes e poder no telejornal: o funcionamento do discurso reportado no Jornal Nacional da Rede Globo, trata de sua pesquisa central sobre "ponto de vista" na perspectiva bakhtiniana. A autora analisa as vozes e o poder no telejornalismo, discutindo sobre o poder do editor e dos jornalistas na elaboração da notícia no programa diário "Jornal Nacional" da rede Globo e o poder de manipulação do público, usando estratégias discursivas que fazem crer que a notícia desse jornal é detentora de verdade.

O artigo de Ana Maria Nápoles Villela; Liliane de Oliveira Neves e Natália Moreira Tosatti (Centro Federal de Educação Tecnológica de Minas Gerais - CEFET), Relações de poder no exame Celpe-Bras, trata das relações de poder no exame para proficiência de língua portuguesa a estrangeiros.

Angela Derlise Stübe e Luiz Fernando Greiner Barp, da Universidade Federal da Fronteira Sul, em A gramática do réu: a objetivação do assassino como exercicio de poder, examinam os discursos jornalístico e policial, tendo como vertente teórico-metodológica o conceito de "arquegenealogia" de Foucault e o conceito de heterogeneidade 
Linha D’Água (Online), São Paulo, v. 30, n. 1, p. 1-7, jun. 2017

enunciativa discussões de Authier-Revuz. Discutem como esses discursos constroem a figura do réu, escondendo saberes e poderes em circulação na sociedade.

Guaraciaba Micheletti (Universidade Cruzeiro do Sul) publica $O$ discurso poético e as relações de e com o poder na poesia de Cacaso, relacionando a literatura com o contexto histórico. A autora propõe uma discussão sobre a ironia na poesia do poeta mineiro Cacaso, um dos representantes da poesia marginal dos anos 1970, tendo como base teórica conceitos advindos da Estilística, Linguística textual e Análise dialógica do discurso. A autora apresenta um profundo estudo sobre as relações de poder construídas em uma minuciosa análise da coletânea poética, considerando o fato de que o poder do discurso poético, por meio da palavra, reflete e refrata a situação político-social brasileiro no momento em que foi produzido.

O número traz também a resenha que Paulo Gonçalves-Segundo e Douglas Rabelo de Sousa (Universidade de São Paulo) propõem sobre a obra Discourse, Grammar and Ideology: Functional and Cognitive Perspectives, de Christopher Hart, professor da Lancaster University, Reino Unido, um estudioso da Análise Crítica do Discurso. O autor, que teve seu livro publicado em 2014, esclarece sobre as relações entre gramática, discurso e ideologia, ao apontar para o papel que as gramáticas como modelos de linguagem podem desempenhar no esclarecimento de marcas ideológicas de textos e discursos em contextos sociais e políticos.

Registra-se, uma vez mais, o agradecimento pelo auxílio recebido do SIBi, Sistema Integrado das Bibliotecas da Universidade de São Paulo, especialmente, por meio do Plano de Incentivo à Publicação de Periódicos da USP-2016, por ser indicativo da crença na produtividade científica de Linha d'Água e no intercâmbio de conhecimento entre pesquisadores e professores do ensino básico e superior.

Assim, esperamos que este número da Linha D’Água possa despertar o interesse e suscitar ainda mais a discussão sobre os problemas da argumentação colocados pelos autores presentes nesta edição.

Junho 2017 
Linha D’Água (Online), São Paulo, v. 30, n. 1, p. 1-7, jun. 2017

\section{Referências}

AQUINO, Zilda G.O. Relatório Pós-Doutoral. Universidade do Minho. Portugal, 2015.

BAUMAN, Zygmunt. Identidade. Trad. Carlos Alberto Medeiros. Rio de Janeiro: Zahar, 2005.

FAIRCLOUGH, Norman; WODAK, Ruth. Critical discourse analysis', in T. van Dijk (ed.). Discourse Studies: A Multidisciplinary Introduction. Volume 2. London: Sage. 1997.

FOUCAULT, Michel. A arqueologia do saber. 3 ed. Trad. Luiz Felipe Baeta Neves. Rio de Janeiro: Forense-Universitária, 1987.

HALL, Stuart. A identidade cultural na pós-modernidade. $11 \mathrm{ed}$. Trad. Tomaz Tadeu da Silva e Guaracira Lopes Louro. Rio de Janeiro: DPeA, 1999.

KERBRAT-ORECCHIONI, Catherine. Génèse et décodage des contenus implicates: compètence des sujets parlants. Paris: Armand Colin, 1986.

VOLOSHINOV, Valentin. Le discours dans la vie et le discours dans la poésie. In: TODOROV, Tzvetan. Mikhail Bakbtine: le principe dialogique. Paris: Seuil, 1981. p. 181-215. 